\title{
An Analog Electronics Mobile Course with a Competitive Learning Approach
}

\author{
$\underline{\text { doi:10.3991/ijim.v4i4.1415 }}$ \\ R.N. Madeira ${ }^{1}$, V.F. Pires1 $1^{1,2}$, O.P. Dias ${ }^{1,3,4}$ and J.F. Martins ${ }^{5}$ \\ ${ }^{1}$ Instituto Politécnico de Setúbal, Setúbal, Portugal \\ 2 CIEEE - Center for Innovation in Electrical and Energy Engineering, Lisbon, Portugal \\ ${ }^{3}$ CESET - Centro de Estudos de Sistemas Electrónicos e de Telecomunicações, Setúbal, Portugal \\ ${ }^{4}$ INESC-ID - Instituto de Engenharia de Sistemas e Computadores, Lisbon, Portugal \\ ${ }^{5}$ CTS, UNINOVA, Universidade Nova de Lisboa, Monte da Caparica, Portugal
}

\begin{abstract}
In the last years several mobile learning courses have been experimented. The increasing popularity and additional features of mobile devices is one of the key reasons for mobile learning courses development. The superior portability and accessibility of those equipments makes them suitable for remote and interactive learning courses. In this context, this paper focuses on the implementation of a mobile learning framework for an analog electronics course. This course was designed as a complement to the classic analog electronics courses. This course consists of several interactive multimedia modules, at the end of which students have to answer several oriented questions. These give feedback about the learning process to the teacher, which receives SMS messages with the results. A specific module is responsible for storing and managing the answers in a server, where all the results from students are processed in a competitive learning based methodology application.
\end{abstract}

Index Terms-Mobile learning, mobile devices, analog electronics course, competitive learning.

\section{INTRODUCTION}

The extensive use of electronic devices makes the understanding of analog electronics theory fundamental for students. Excellent textbooks covering this subject are constantly being published. Besides that, in the last years, several learning tools based on personal computers have also been developed. Remote and blending learning systems enhance the possibility for students to attend lessons in remote locations, at a physical distance, being able to be at any place and to communicate actively by means of computers and networks. This is why this type of learning has become nowadays increasingly popular. New technologies and methodologies have been used in order to allow students to learn in and outside the traditional classroom.

Nowadays, different learning styles and methodologies can be adopted. We can find large differences in the learning preferences of students. We find those who prefer collaborative activities instead of a competitive approach, and vice-versa. The style chosen by an evaluation is also a key factor in the learning process of a student, because it determines their study procedure until the evaluation time. E-learning systems enhance the possibility for students to attend lessons in remote locations, at a physical distance, being able to be at any place and to communicate actively by means of computers and networks. On the other hand, it is important that students always have the opportunity to acquire their knowledge through traditional means. Balanced blended learning that combines e-learning and learning in the classroom environment is a good solution for specific courses, if not for everyone.

At the present, one of the more innovative and student oriented methodologies is mobile learning (m-learning). M-learning uses mobile devices, like cell phones, Personal Digital Assistants (PDAs) and smart phones. M-learning can be defined as "the exploitation of ubiquitous handheld technologies, together with wireless and mobile phone networks, to facilitate, support, enhance and extend the reach of teaching and learning" [1]. M-learning is a relatively recent concept, but by our group experiences, and by others described in literature, such as [2, 3], it has been motivating students and teachers, representing an effective pedagogical method as any other conventional learning method. Nevertheless, the real problem is still the efficient and suitable adaptation of the courses contents to means with clear restriction factors [4]. The former restrictions are basically visual, technological and social (SMS costs, among others), which are mentioned in several works, generally measuring the impact of the handheld mobile devices in our society [5]. Therefore, in these days, the challenge for teachers is to prepare new courses based in a methodology that embraces the potential of mobile devices, also facing their restrictions. Innovative supporting frameworks should be implemented to accomplish that task. In an initial phase, these frameworks can be directed to specific courses, but they should be extended to accommodate more generic scenarios, being prepared to support almost any course.

The study of analog electronics is fundamental in an electrical engineering course. A basic understanding of electronic theory is necessary for electronic systems operators, maintenance personnel, engineers and the technical staff to safely operate, maintain and support electronic. Electronic theory knowledge is a fundamental issue to help these technical staff to fully understand the impact that their actions may have on the safe and reliable operation of electronic systems. Generally, in these courses, classical teaching uses textbooks as the main element. However, the use of textbooks is very limited, too flat and static. However, in this new technological context, it is important to develop new m-learning tools for these courses. 
Therefore, a new m-learning framework for the analog electronics course was developed at Superior School of Technology of Setubal (Polytechnic Institute of Setubal). The initial course material has been adapted to the mlearning environment and new contents were added, enriched with animations and interactive examples. Besides the traditional theoretical lessons, and laboratory practices, we propose the use of this m-learning system to reach a wider target. The presented approach includes a competitive learning module, applied to the usual individualized and cooperative settings. We consider it essential for the growth of our students facing a very competitive global society. This article describes the implemented course, the learning approach and the main points of the supporting computational framework.

\section{BACKGROUND LEARNING CONCEPTS}

Nowadays, mobile devices are essential tools for our daily living. With the evolution of their technologies, we see people adapting more easily to the use of the devices. According to [6], the mobile revolution is already here. At the same time, with the evolution of the available functionalities, it also increased the diversity and capacity of multimedia options and wireless communication technologies of the devices. Seen as small computers, these devices can support diverse lessons, display animations for any kind of contents, be used for polling and testing, serve as a gateway to larger learning resources, among much more options.

With the fast growth of wireless handheld and mobile devices sales (Fig. 1), it has started to rapidly emerge the m-Learning concept as a new instructional method. Mlearning is characterized by mobility and accessibility, since it focuses on the use of handheld mobile devices. These equipments have become very popular, especially among young people who use them not only for communication but also as a tool for other activities. There are almost one and a half billion mobile phones in operation around the world, and a large percentage of them are in the hands of students. In the coming 10 years, whether educators want it or not, more and more students will bring computing devices into the classrooms.

In addition to the ordinary mobile phones, these devices can even be netbooks, notebooks and mobile music players, among others.

For the development of the proposed project, it is important to have in mind that sophisticated and smart phones are increasing their sales in comparison to the basic cell phones (Fig. 1). Additionally, looking to Figure 2, it is possible to establish a guideline between those sales and the increased use of advanced functionalities in mobile phones. These are important arguments, because the mobile application of the present work uses multimedia content and some connectivity options. Therefore, this is considered as a positive factor since the probability of finding devices with capabilities for playing lessons and testing contents is high, being excellent to the production of mobile applications with higher performance and better multimedia content.

As far as the use of these tools in education is concerned, not all courses are suitable for m-learning environments, but short courses are considered suitable for this kind of learning [8]. The use of quizzes, glossaries and the interaction with tutors and other peers may satisfy a wide

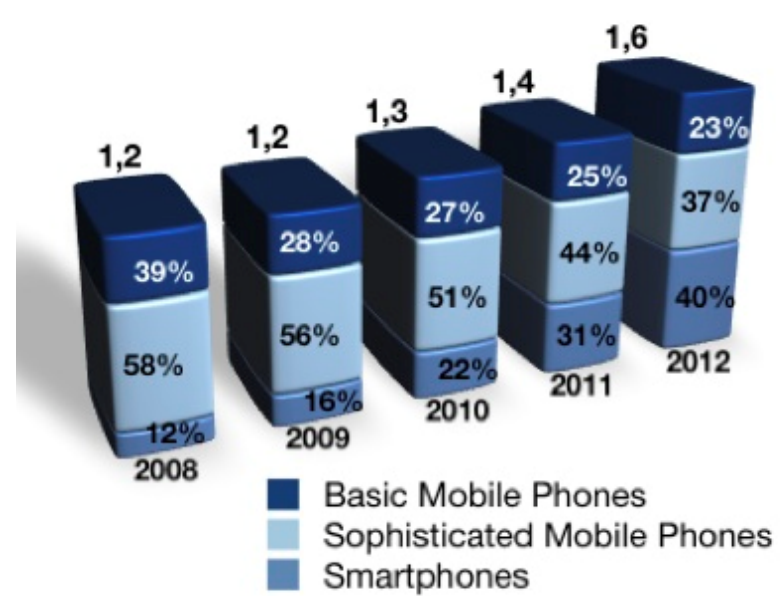

Figure 1. Number of mobile phones sold per year, worldwide [7].

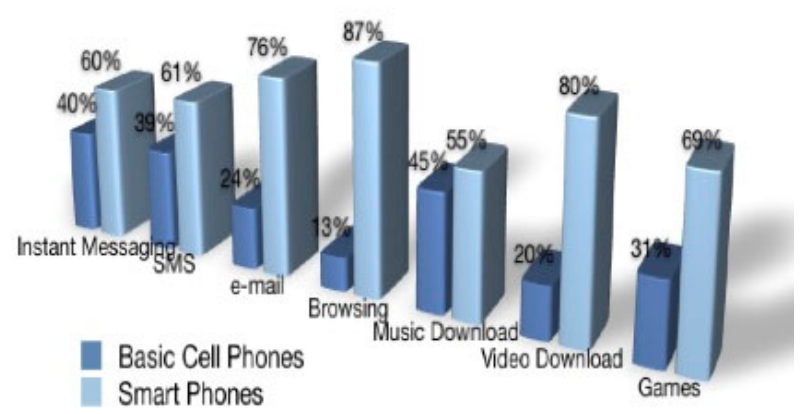

Figure 2. Advanced functionalities used in basic phones and smart phones [7].

range of needs and aims on behalf of students. Communication can be made through e-mails, SMS and MMS, and it is important for students to have feedback about their progress [8].

Johnson and Johnson suggested that an effective classroom must have the right mix of cooperative learning and competitive learning (along with individualized learning) [9]. Cooperative learning encourages students to work with and learn from each other. Alternatively, a competitive learning implementation places students against each other competing for best results [9]. For example, if a student gains a point, his competitor does not win anything. In a competitive setting, students judge their abilities to master content and knowledge relatively to their competitors. In the business world people often work on a variety of team settings and cooperative activities. The context of the classroom should provide to students training for the business life and offer them some insights regarding competitiveness at work. The cooperative aspect of this set of activities may also offer a better learning environment to students. The cooperative component embedded into competitive learning represents a potential complement that may help to engage students. Once they are faced against each other, their competitive instincts can encourage them to increase their engagement in the learning process. Students who initially may not be inspired by the content may begin to be interested once they have to compete, seeing that like a game. Students must be prepared 
for all the adverse situations in an increasingly competitive workplace environment that they will face after finishing their graduation.

\section{RELATED WORK}

This section presents important related work, although we did not find m-learning systems delivering the pretended analog electronics course.

With the rapid development of ICT systems, new educational opportunities and instructional methods appeared. Therefore, several e-learning tools have been developed to enhance the learning process in analog electronics courses $[10,11,12,13,14]$. However, these solutions do not have modules directed to m-learning, with the presentation of the functionalities and features required by our proposal.

It has to be noted that, nowadays, m-learning is a very active research field, with the development of important and interesting projects. In [15], Frohberg et al. made a deep and critical analysis of mobile learning projects published before the end of 2007. Mobile learning is rapidly growing from a set of research projects into worldwide deployment of services for classrooms, field trips, workplace training and informal education, among other areas. Major projects have concentrated on the generic platforms development for m-learning and explored new supports for a kind of technology-mediated learning across locations and life transitions [16, 17]. Smaller projects are more directed to develop new pedagogical solutions for specific cases and to explore how learning on handheld mobile devices interweaves with personal interests and individual learning needs [18].

In relation to platforms, the following projects support the implementation of specific mobile and wireless applications for mobile devices, such as the MOBIlearn project [19]. It pretends to deliver a generic m-learning architecture to support creation, brokerage, delivery and tracking of learning and information contents, using ambient intelligence, location-dependence, personalization, multimedia, instant messaging (text, video) and distributed databases. Another proposal, MADEE [20], is an execution environment and application development tool that supports and makes easier the development of mobile and wireless information systems that run on handheld devices, allowing communication and information sharing among users in an organization. Other older examples are: the Sync a Java framework [21] that allows asynchronous collaboration between mobile users; Rover [22], a framework for building mobile applications based on flexible client/server architecture; and LIME [23], a middleware package written in Java that supports mobile application development and coordination.

An interesting application of m-learning has been carried out by the Standford Learning Lab for the teaching of the English language [24]. Quizzes, glossaries and interactive audio-files were sent to students to improve their pronunciation and language competencies/skills. Interesting to us is that two other language experiences were followed for the acquisition of English vocabulary and idioms on mobile devices. The first one does it through SMS and the second by means of videos. Another application of mobile learning in the study of languages is Pocket Eijiro [25], an English-Japanese, Japanese-English dictionary, which presents some interesting features.
On the other side, the Moop [26] m-learning environment was developed for use in primary school at the city of Oulu, Finland. Moop has an interactive application for use in situations where primary school students take use of a cell phone to analyze their surroundings and to communicate within groups. The system supports the process of inquiry learning, during which a user outlines her thoughts on the current topic, collects information from the surroundings and reports the findings to the system. The HandLeR project [17], one of the oldest, is an attempt to gain an in-depth understanding of the learning process in different scenarios with the evaluation of a handheld device. The system is also "...intended to support children to capture everyday events such as images, notes and sounds, to relate them to web-based learning resources, to organize these into a visual knowledge map and to share them with other learners and teachers" [27]. This kind of systems promotes learning in complex scenarios where learning goals depend on a contextual factor.

Another system, related with context, is "Contextual Cues" that lets students, who have attended a lecture, to receive a copy on their mobile phone of key points that the teacher labels as important, which should be reviewed later [28]. To support this, a plug-in or application installed on the teacher's Bluetooth-enabled computer makes it easier to highlight important points in the teaching material. During the presentation, the broadcasting of the key points together with a timestamp takes place in parallel with the presentation of the related material.

Regarding quiz systems oriented for mobile devices, there are several commercial and free options that are interesting for our study. Moodle for mobile tests [29] is a module to execute Moodle questionnaires using CHTML (compact HTML) in compatible mobile phones with imode technology. Interactive test is a module of an mlearning system [30] specifically developed for use in Java-enabled mobile devices. Go Test Go’s [31] is a commercial quiz system designed to be used in Java mobile phones which provides a great selection of quizzes about several areas. Finally, Quizzler [32] is a commercial product designed for PC, Palm and PocketPC platforms and provides a collection of tools (quizzler reader, quizzler software maker and quiz library).

\section{DESCRIPTION OF THE MOBILE COURSE}

This course is composed by two main modules: the learning module where students can study analogue electronics and the competitive module where students are selected to participate in a tournament.

\section{A. Learning Module}

The pedagogical goal of this course is to introduce students to the most relevant concepts in analogue electronics. On the other hand, the technological goal of this project is the implementation and testing of an m-learning concept tool that integrates a competitive module. The purpose of this solution is not to replace the traditional teaching methods, but to create a complementary tool in order to improve the student's interest, motivation and the resources availability in any place, at any time.

Teaching analogue electronic circuits presents several problems for teachers and students. One of the main problems is that voltages and currents are not directly visible and must be measured indirectly with meters and oscillo- 
scopes. To overcome this problem, simulators and multimedia animations can be used, avoiding a passive watching of the display and "forcing" an active participation in the learning process.

The m-learning analogue electronics course consists in several interactive modules. The contents of the modules cover the following main topics:

- Semiconductors theory

- PN junction theory

- Diodes and applications

- Transistor and applications

The contents were developed in order to put an emphasis on demonstrating and assisting each theoretical concept with a practical application. Another important goal is the use of rich multimedia content, such as images and interactive animations, which are also essential for the understanding and motivation of the students. One important feature associated with these contents is an option for comments. This way, students can make annotations and give feedback about those contents. With students' annotations, teachers can verify if those figures and interactive animations are clear or if they have to be improved. From those comments, teachers can also have some information about the student's knowledge. When students select the option to give feedback, an SMS will be sent to the teacher with the annotations.

In order to provide to the student an evaluation of his knowledge progress, at the end of each module there are several quizzes about the module. This can also help the teacher to verify the student's progress. At the end of the evaluative quizzes, if possible, an SMS is sent to the teacher, informing about the answers results to the questions. In case of failure, the student must start again the lesson. New quizzes will also appear and, in order to avoid the same questions, there is a large variety of quizzes that are generated from a teacher contents manager application.

The lessons are simple in order to avoid excessive information for students. However, in several pages there is an option called "to know more". So, the amount of information presented to students is adapted to their needs.

\section{B. Interfaces Design Examples}

As an example of interfaces, Fig. 3 shows an animation about the semiconductor theory. With this image, students can see the formation of a PN junction diode and the movement of electrical charges.

On the other hand, Fig. 4 shows an interactive circuit for the full-wave bridge rectifier circuit with a resistor load. Students can see the directions of the currents and the input, diode and output voltages. They can also change the amplitude of the input voltage and turn on or off the displayed voltage waveforms.

Other animations have been used in this m-learning course. Fig. 5 shows an interactive figure about the semiconductor theory. With this figure, students can see the movement of the electrical charges inside of the silicon crystal. They also can change the value of the input source voltage.

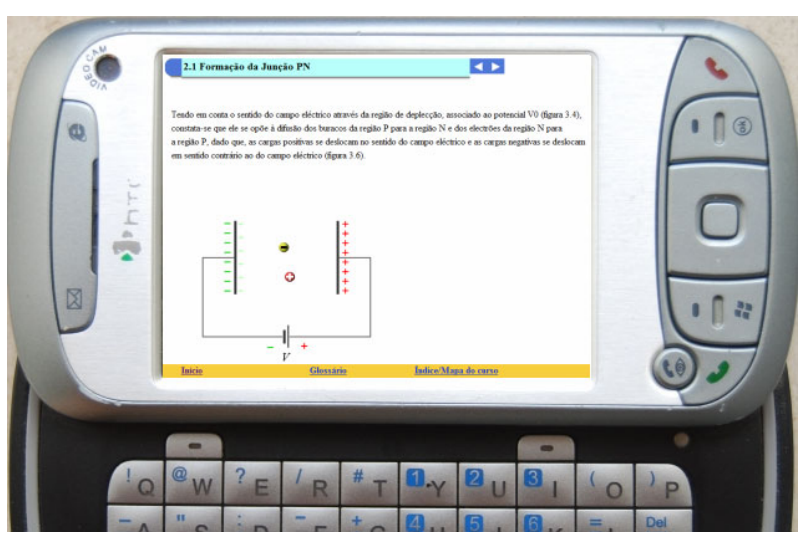

Figure 3. Animated figure about the formation of a PN junction diode.

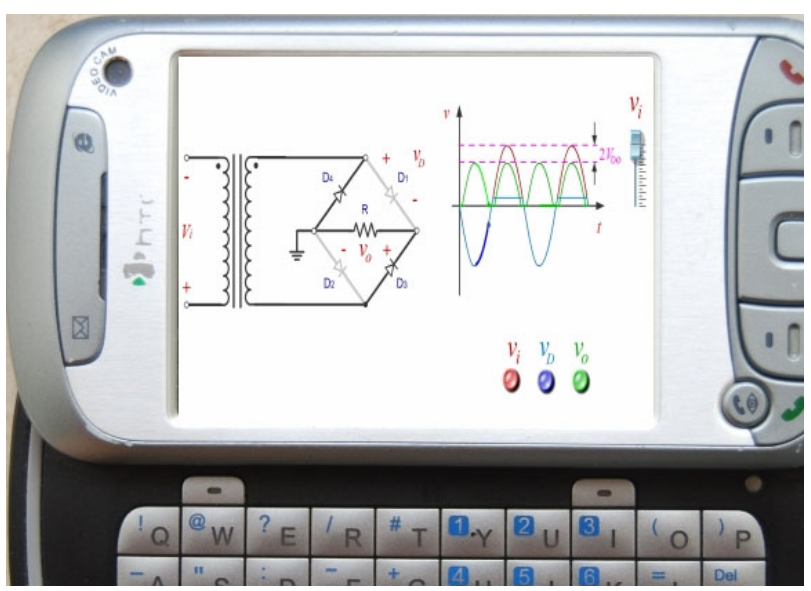

Figure 4. Interactive figure for the full wave bridge rectifier.

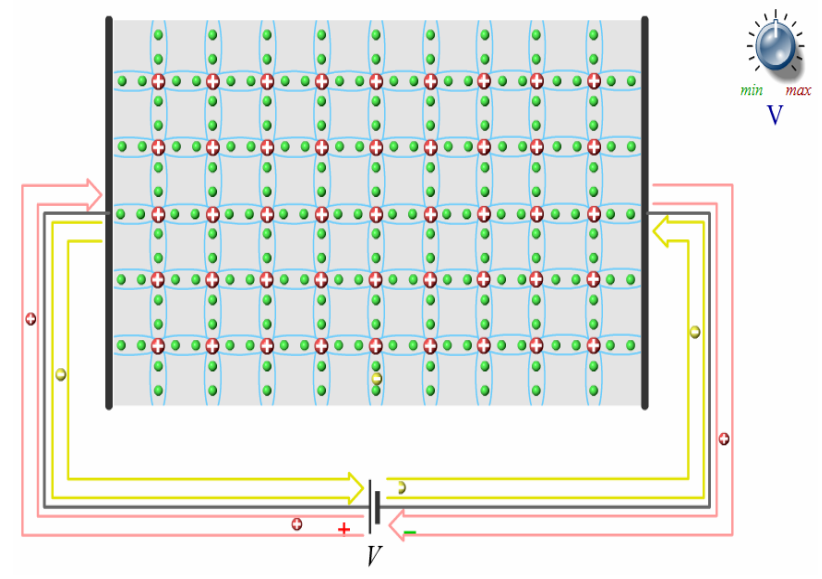

Figure 5. Interactive figure about the semiconductor theory.

Fig. 6 shows another interactive circuit that has been developed to explain the voltage doubler rectifier. With this circuit, students can change the speed of the circuit simulation. Fig. 7 shows an animation that allows students to know how to measure a diode. Clicking with the mouse on the meter they see what happens when the diode is measure in a forward way or in an inverse way. This figure shows what the students see in different moments. 


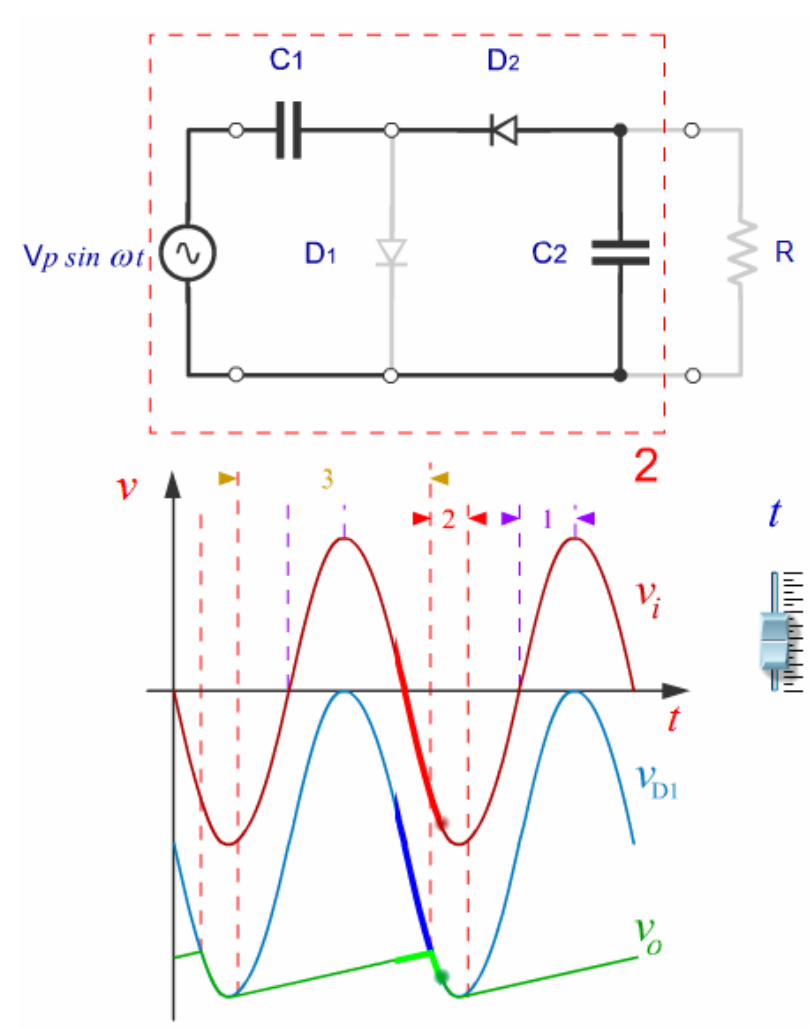

Figure 6. Interactive figure for the voltage doubler rectifier.

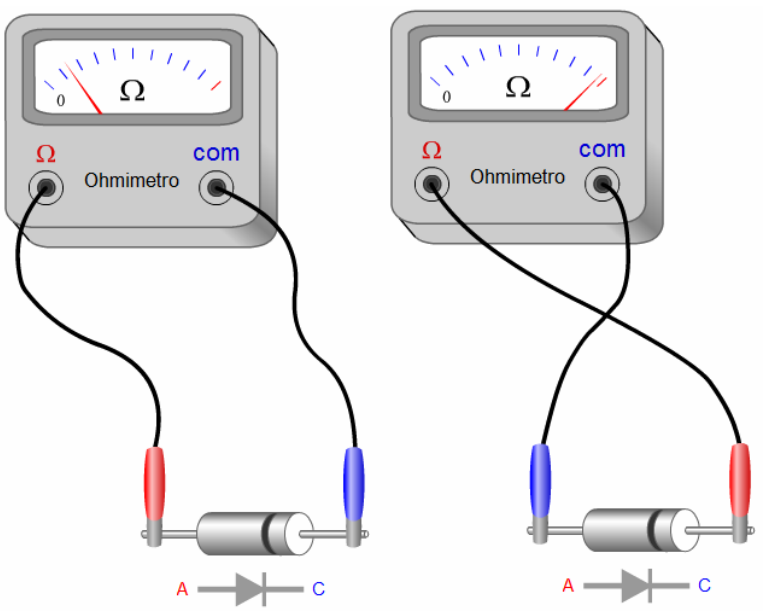

Figure 7. Interactive figure for the measure of a diode.

\section{Competitive Learning (CL) Module}

The competitive module implements a competition where the mobile students are selected to participate in a tournament similar to the well known UEFA ${ }^{\circledR}$ football champions league, with a groups' stage and a knockout phase. This module is under development, being almost finished and in a phase of integration in the platform system.

For the competition, the students use the mobile device client application to answer to quizzes like the aforementioned ones for the auto-evaluations. One game is composed by a randomly generated quiz, being "played” by a student against an opponent and the clock. At the end of a game, the answers are automatically stored in the mobile device and sent to the server. The mobile application knows the games' results of the corresponding user/student, but the central CL application of the MoCoL framework (Section V) needs to have access to all the quizzes results, from all users. So, every now and then the applications must be synchronized with the central system, with the connection being made automatically at distance or established in the classroom. The framework automatically evaluates the obtained answers for the proposed game, elaborating the classification and managing future games.

The competition can take place for several sessions (lessons, marked days, etc.) and a teacher can configure it choosing, for example, the beginning time of the different group games, the level of the games (quizzes to be answered), the competition mode (auto-evaluation/training, assessment, or friendly), among other parameters. One additional parameter is the submission type of the results, which can be through the normal option or sending an SMS to the teacher at the end of the game.

Additionally, in the future, it will be possible for a student to submit to the database, and for a CL tournament edition, quizzes questions to be answered by his colleagues. This is one of the most interesting functionalities in our methodology, since this can improve the learning performance of a student which has to know and find more exercises indicated to propose to others.

\section{The Mobile And Competitive LeARning (MOCOL) FRAMEWORK}

The present section presents the MoCoL framework, highlighting the main requirements, the supporting architecture, the development of the course mobile application and technologies used in the implementation.

\section{A. Requirements}

When implementing a new methodology and designing a framework like the one presented within this work, first, we have to establish some principles and requirements. Therefore, to support and complement the course lessons it is highly desirable to have a computational system working with the following main goals: to allow the mobile learning to run in a motivating setting; to flexibly the timetables for learning in order to complement classroom lessons, which can be important for workers; to allow the student auto-evaluation; to allow recovery modules in order to give to all students the same opportunities; and to add the option to be used interactively in different kinds of classroom lessons.

MoCoL uses four main end-users groups as system requirement. They are students, teachers, administrators and even parents. Students are the main end-users because they get numerous benefits from the system. The system provides notes and tutorials for the students to learn more about the subject. Besides, it has information about other links related to the chapter.

Teachers can use the platform as a teaching tool by looking at the lesson, tutorial and other links that will be provided by the system. Besides, teachers play an important role providing questions to the quizzes section. The system provides a function of auto-calculation, making the quizzes more or less difficult, according to the integration of questions. The teachers have to update the chapters' contents. Teachers also receive email from the students or their parents regarding students' performance. Thus, the 
system provides good relations between teachers and students, as well as with the parent(s).

The administrator has the role to access most of the functions in the system. This is because s/he has to update and configure the system to meet the requirements of teachers.

Parents use MoCoL to guide their children's performance in the course. They can check how many times their children have accessed the study material and what exactly they do when entering the system. The parents will have a log file in their module for this purpose.

\section{B. System's Architecture}

The architecture of the global system is the typical client-server solution with the two-tier separation (Fig. 8). The clients are the following: a web tool (e-learning) module, available through a web browser; an off-line module that is an e-book, or interactive DVD (iDVD), being easily carried by students; and the m-learning tool, with a competitive module and a reduced version of the elearning contents.

The architecture for the mobile client includes three main layers (Fig. 9): authentication, interface and specific services. The top layer is responsible for the authentication process, currently presenting two main sub-modules for management of students and teachers functionalities. Students login to access to the contents of the lessons or to compete in a CL tournament, submitting results through the module. It is also possible to submit new exercises to be played in a CL tournament. The module related with teachers integrates all the functionalities necessary for the correct management of the competitions and students monitoring. One teacher can add new exercises, with the corresponding type descriptors, to the database and configure CL tournaments, which can be formative, at the end of lessons, or for evaluation purposes. Through this submodule, teachers access the Automated Evaluator (AE) sub-module, configuring it according to the class of students they have in mind to compete.

The course interface layer integrates the two options: the analog electronics course material and lessons; and the module that implements a competitive tournament among students.

The bottom layer includes the services specific modules. One of them is the manager of classifications and featured tournaments, which is used both for the competitive tournaments and for the management of the quizzes at the final of the lessons. All the information is synchronized through the central database of the system. The Automated Evaluator sub-module crosses the submitted results with the configuration made by teachers and the exercises descriptors taken from the database to evaluate how many goals were "scored" by students. It is a service of the competitive learning sub-module. On the other hand, the SMS feedback is a service for the learning course as it manages the communication between devices, registering the overall results to the quizzes and comments to course's contents.

\section{The MoCoL Mobile Application Specifications}

The MoCoL client is a mobile application developed in Java (J2ME) for devices that support the MID profile. This application allows the user to interact directly with the system's server and indirectly with other users.

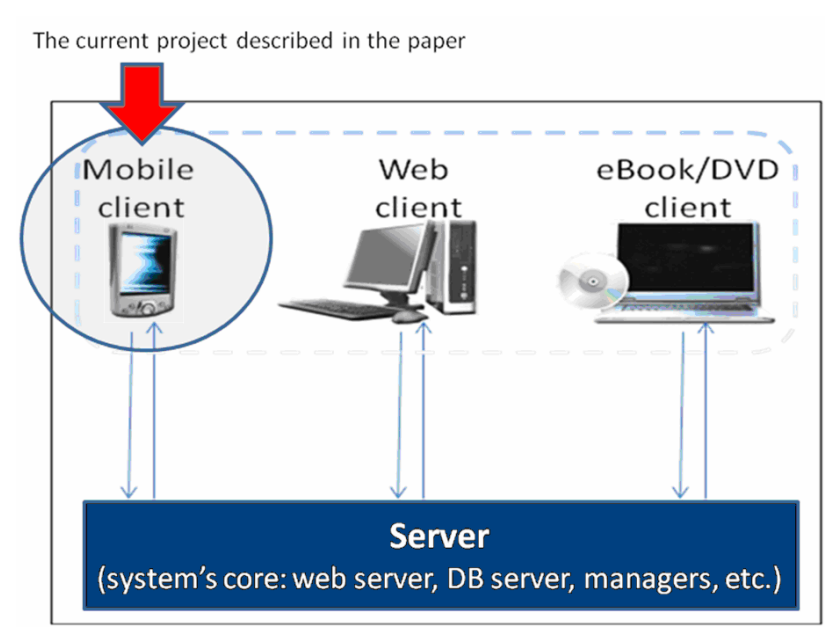

Figure 8. Client-server architecture of the framework.

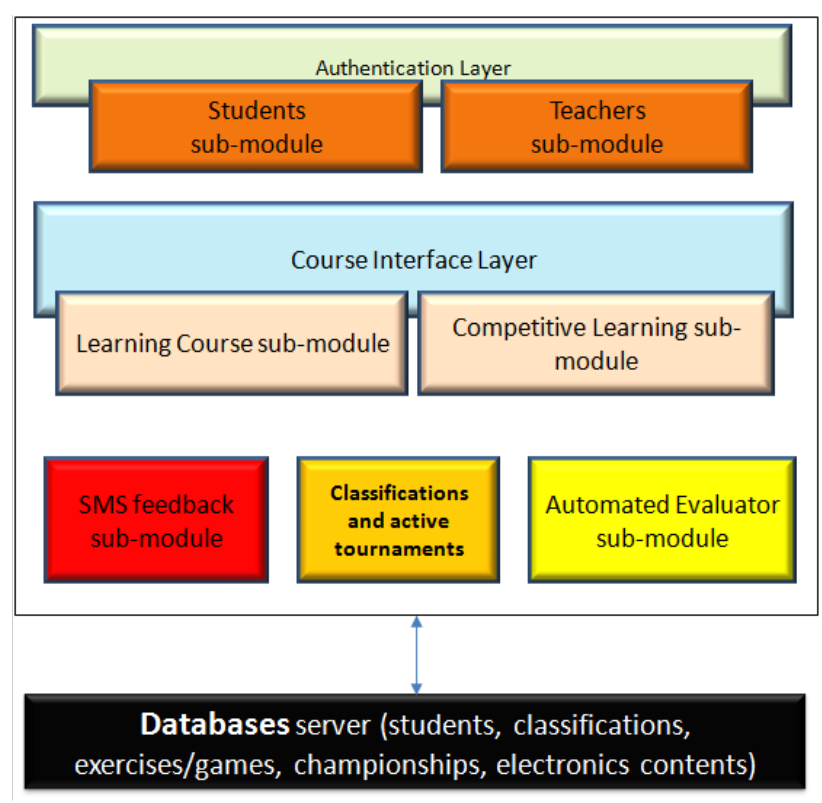

Figure 9. Architecture of the mobile device application.

This client application is generic, in the sense that it is independent of the server-side applications. The application relies on APIs (Application Programming Interfaces) that were designed in an independent way relatively to the implemented prototype. It has two main modules: one with functions to interact with the server via Bluetooth and another one to manage the possible information received from the system. Therefore, the client application uses the JSR-82 and the BlueCove APIs as the server application also does.

Not all the mobile devices can run the first module to interact directly with the system. To accomplish that, the device must be embedded with the JSR-82 API. If a device does not embed the API, a possible solution is the implementation of a web server, making available an URL address to be accessed through the WAP browser of the mobile device. In this way, a student will be able to receive XML documents to consult later and to store them in the client repository, a Record Management System (RMS).

The module to manage the received information uses the kXML library in its implementation to make the pars- 
ing of the XML documents. kXML provides an XML pull parser and writer suitable for all Java platforms, including J2ME. Because of its small footprint size, it is specially suited for Java applications running on mobile devices.

\section{CONCLUSIONS AND FUTURE WORK}

The use of m-learning tools, if correctly conceptualized and built, constitutes an efficient complementary tool to the traditional teaching methods. So, in this context, it was presented the development of a mobile learning framework for analog electronics course. The theoretical content of the course was structured in several interactive modules. At the end of each module, there are quizzes allowing students to be evaluated by themselves or by course teachers. The teacher receives automatic SMS from the student's mobile phone. This allows the teacher to have access to the student's progress and comments about the images and multimedia animations.

As future work, it is pretended to study how to overcome some disadvantages found in m-learning, such as its high costs, the possibility for mobile devices to be misplaced or stolen and the difficulty to use mobile devices in noisy environments. Yet, another future step will be in the direction of creating the best interfaces to deal with the small screen size of the devices, the limited memory size, the small keyboards and limited battery life, among other issues.

Another important point for future work is the dissemination of the results of a questionnaire survey that is already being carried out among the students of the course.

\section{REFERENCES}

[1] Mobile Learning Network (MoLeNET), What is Mobile Learning?, http://www.molenet.org.uk/.

[2] C. Romero, S. Ventura, and P. Bra, Using Mobile and Web-based Computerized Tests to Evaluate University Students, Computer Applications in Engineering Education Journal, vol. 9999, Published online in Wiley InterScience (www.interscience. wiley.com), 2009, doi:10.1002/cae.20242

[3] M. Sharples, J. Taylor, and G. Vavoula, Towards a Theory of Mobile Learning, Proc. of 4th International Conference on mLearning - mLearn Conference,Cape Town, South Africa, 2005.

[4] G. Avellis, A. Scaramuzzi, and A. Finkelstein, Evaluating Non functional Requeriments in Mobile learning Contents and multimedia educational software, Proc. of Int. Conf. MLEARN 2003 learning with mobile devices, London, May 2003.

[5] A. Oulasvirta, Human-computer interaction in mobiles context: a cognitive resources perspective. Licentiate Thesis, Faculty of Behavioral, University of Helsinki, 2004.

[6] E. D. Wagner, Enabling Mobile Learning, EDUCAUSE Review, 40(3), 2005, 40-53, Available at: http://www.educause.edu/ apps/er/erm05/erm0532.asp.

[7] P. M. Santos, A hora dos supertelemóveis, Visão, 0(854), 16-22 Jul 2009, 48-52.

[8] M. L. Vinci, and D. Cucchi, Possibilities of application of e-tools in education: mobile learning, Proc. Conf. on ICT for Language Learning, Florence, Italy, 2007.

[9] D. W. Johnson, and R. T. Johnson, Learning together and alone: cooperative, competitive and individualistic learning (fifth edition). Needham Heights, MA: Allyn \& Bacon, 1998.

[10] J. J. Zamora, A. J. Mazón, A. Torrens, and H. Pujana, Educational Application with an Internet On-Line Spice Simulation, Proc. 12th IEEE Mediterranean Electrotechnical Conference, Dubrovnik, Croatia, 2004, pp. 421-424. doi:10.1109/MELCON.2004.1346901

[11] C. Pais, V.F. Pires, R. Amaral, J. Amaral, J.F. Martins, C. Luz, and O. P. Dias, A Strategy to Improve Engineering Teaching
Process Based on an E-Learning Approach, Proc. 5th International Conference on Information Technology Based Higher Education and Training, Istanbul, Turkey, 2004, 1-4.

[12] J.J. Zamora, and I. Larrafiaga, SIMULA 2000: an Internet Based Working Environment for the Support of Educational Applications in the Field of Electronics, Proc. 31st Annual Frontiers in Education Conference, Reno, NV, 2001, F1F-11-16.

[13] L. Esteves, and V. F. Pires, WPEC - A New Web Tool for the Power Electronics Learning, Proc. 31th Annual Conference of the IEEE Industrial Electronics Society, Raleigh, USA, 2005, 21522155.

[14] M.A. Khan, A.W. Siddiqui, and M. Abdul-Majid, Interactive Learning for Waveform Dynamics of Diode Rectifiers and RC Filter in DC Power Supply, Proc. 34th Annual Conference of the IEEE Industrial Electronics Society, Orlando, FL, 2008, 35303534.

[15] D. Frohberg, C. Göth, and G. Schwabe, Mobile Learning projects - a critical analysis of the state of the art, Journal of Computer Assisted Learning, vol. 25, no. 4, August 2009 , pp. 307-331(25).

[16] C. H. Muntean, and G. Muntean, Open Corpus Architecture for Personalised Ubiquitous E-learning. Personal Ubiquitous Computing journal, vol. 13, no. 3, 2009, pp. 197-205.

[17] M. Sharples, The Design of Personal Mobile Technologies for Lifelong Learning, Computers and Education, vol. 34, no. 3, 2000, pp. 177-193. doi:10.1016/S0360-1315(99)00044-5

[18] A. Hamid, and S. Hafizah, WE-learning - Electronic and Mobile Learning Environment, The Public Institutions of Higher Learning R\&D Exposition, Kuala Lumpur, Malaysia, 2003.

[19] MOBIlearn project website, MOBIlearn - the wings of learning, http://www.mobilearn.org/.

[20] G. Licea, L. Aguilar, J. R. Juárez, and L. G. Martínez, Teaching Mobile and Wireless Information Systems Development in Engineering Courses, Computer Applications in Engineering Education Journal, vol. 9999, Published online in Wiley InterScience (http://www.interscience.wiley.com), 2009, doi:10.1002/cae.20251

[21] J. P. Munson, and P. Dewan, Sync: A Java framework for mobile collaborative applications, IEEE Computing, vol. 30, 1997, pp. 59-66.

[22] A. D. Joseph, J. A. Tauber, and M. F. Kaashoek, Mobile computing with the Rover toolkit, IEEE Trans Comput, vol. 46, 1997, pp. 337-352. doi:10.1109/12.580429

[23] G. P. Pico, A. L. Murphy, and G. Roman, Developing mobile computing applications with LIME, Proc. of Int. Conf. on Software Engineering, Limerick, Ireland, 2000, pp. 766-769.

[24] P. Thornton, and C. Houser, Using mobile phones in English education in Japan, Journal of Compute Assisted Learning, 21, 2005, 217-228. doi:10.1111/j.1365-2729.2005.00129.x

[25] Japan media review, Language E-Learning on the Move, http://www.ojr.org/japan/wireless/1080854640.php.

[26] P. Mattila, MOOP - Mobile Learning Environment As Part Of Daily School Work, Proc. Conf. on Microlearning 2005. Learning \& Working in New Media, Innsbruck, Austria, 2005, 141-156.

[27] M. Sharples, D. Corlett, and O. Westmancott, The Design and Implementation of a Mobile Learning Resource. Personal and Ubiquitous Computing, Vol. 6, No. 3, 2002, pp. 220-234. doi:10.1007/s007790200021

[28] M. Voong, Contextual Cues: Aiding Wireless Multimedia Collaborative Learning, Beyond Mobile Learning Workshop, Switzerland, 2007.

[29] Mobilemoodle.org, Momo (Mobile Moodle) Project, http://www.mobilemoodle.org/momo18/, 2009.

[30] M. C. Mayorga, and A. Fernandez, Learning, tools for java enabled phones: An Application to Actuarial Studies, Proc. of the International Conference Mobile Learn, London, 2003, pp. 95-98.

[31] Go Test Go Inc., Go test go system, http://www.gotestgo.com/, 2009.

[32] Pocket Mobile Inc., Quizzler Pro, http://www.quizzlerpro.com/, 2009. 


\section{AuTHORS}

R. N. Madeira is a teacher at the Department of Systems and Information Technology, Technology Superior School, Polytechnic Institute of Setúbal, Setúbal, 2910761 Portugal, and a researcher at CITI/DI, Faculdade de Ciências e Tecnologia da Universidade Nova de Lisboa (e-mail: rui.madeira@estsetubal.ips.pt).

V. Fernão Pires is with the Department of Electrical Engineering, Setúbal School of Technology, Polytechnic Institute of Setúbal, Setúbal, 2910-761 Portugal (e-mail: vitor.pires@estsetubal.ips.pt).
O. P. Dias is with the Department of Electrical Engineering, Setúbal School of Technology, Polytechnic Institute of Setúbal, Setúbal, 2910-761 Portugal (e-mail: pascoa.dias@estsetubal.ips.pt).

J. F. Martins, is with the CTS-UNINOVA and Faculdade de Ciências e Tecnologia, Departamento de Eng. Electrotecnica, 2829-516 Caparica, Portugal (e-mail: jf.martins@fct.unl.pt).

Submitted, July, 30, 2010. Published as resubmitted by the authors September 27, 2010. 